\title{
A FRATERNIDADE COMO PRINCÍPIO ÉTICO NECESSÁRIO PARA UMA NOVA PRÁXIS COLETIVA E EMANCIPATÓRIA EM DIREITOS HUMANOS
}

\section{THE FRATERNITY AS AN ETHICAL PRINCIPLE FOR A NEW COLLECTIVE AND EMANCIPATORY PRACTICE IN HUMAN RIGHTS}

\begin{abstract}
FRANCISCO PIZZETTE NUNES
Mestre em Direito pelo Programa de Pós-Graduação em Direito da Universidade Federal de Santa Catarina (PPGDUFSC) na área de Direito, Estado e Sociedade. Pesquisador do Grupo de Estudos em Latim e Fontes de Direito Romano: Ius Dicere. Professor e Coordenador do Curso de Graduação em Direito da Escola Superior de Criciúma (ESUCRI).

francisco.pizzette@gmail.com

JOSÉ ISAAC PILATI

Graduado em Direito pela Universidade Federal do Paraná (1973), Mestre (1989) e Doutor (1995) em Direito pela Universidade Federal de Santa Catarina. Professor Associado IV da Universidade Federal de Santa Catarina, $e$ credenciado junto ao Programa de Pós-Graduação em Direito da UFSC.
\end{abstract} jipilati@matrix.com.br

\section{RESUMO}

0 presente estudo trata de pesquisa bibliográfica de método dedutivo que tem por objeto a fraternidade como pressuposto fundamental para 0 desenvolvimento de uma práxis pós-moderna em direitos humanos de cunho coletivo, participativo e emancipatório. 0 estudo se desenvolve em dois momentos. No primeiro preocupa-se em traçar elementos históricos ligados ao reconhecimento do princípio da fraternidade e à ruptura que sofreu no contexto pós-revolucionário francês. No segundo a pesquisa preocupa-se em resgatar a fraternidade enquanto experiência capaz de promover a articulação entre os princípios do Estado e da Comunidade e de promover 0 resgate da democracia participativa dentro de um novo paradigma. Verifica-se que os autores citados caminham na mesma direção, mas os textos não se mostram, no conjunto, definitivos. A participação fraterna e inclusiva deverá desenhar o futuro à base dos problemas concretos.

Palavras-chave: democracia; direito fraterno; direitos humanos; pós-modernidade; sociedade.

\begin{abstract}
The present study is a literature of deductive method that aims at the fraternity as fundamental presupposition to the development of a postmodern praxis of collective-participatory and emancipatory human rights. The study is divided into two objectives. The first is concerned to trace historical information concerning the recognition of the principle of fraternity and the French post-revolutionary schism with the same. The second objective is concerned with rescuing the fraternity while an experience capable of promoting links between the principles of the State and the Community and to promote the return of participatory democracy within a new paradigm. It appears that the authors cited in the present work walk in the same direction, but the ideas do not show definitive. Fraternal and inclusive participation should work future problems from a practical perspective
\end{abstract}

Keywords: democracy; fraternal law; human rights; post-modernity; society. 


\section{SUMÁRIO}

INTRODUÇAO; 1 FRATERNIDADE E COLETIVIDADE: UM PONTO DE RUPTURA EM COMUM; 2 FRATERNIDADE, DEMOCRACIA E PARTICIPAÇÃO POPULAR: RUMO A UMA NOVA PRÁXIS COLETIVA DE CARÁTER INTERSUBJETIVO, DIALÓGICO E EMANCIPATÓRIO; 2.1 A Fraternidade como contributo para uma teoria contra-hegemônica dos direitos humanos; 2.2 A Fraternidade como princípio estruturante de uma nova dimensão de direitos fundamentais; CONCLUSÃO; REFERÊNCIAS.

\section{INTRODUÇÃO}

Este artigo foi produzido, por escolha do Doutorando, entre duas linhas de pesquisa do Curso de Doutorado em Direito da Universidade Federal de Santa Catarina: direito e fraternidade e teoria pós-moderna do direito. Lançando mão de outros autores que estão sendo estudados a propósito dessas duas vertentes do Programa, procura estabelecer uma discussão em dois momentos: fraternidade e coletividade de um lado, desde a ruptura da tríade da Revolução Francesa, e de outro, conclusivamente, na intenção de contribuir para a construção de uma nova teoria dos direitos humanos, partindo do resgate da fraternidade com vistas a uma efetiva participação popular.

\section{FRATERNIDADE E COLETIVIDADE: UM PONTO DE RUPTURA EM COMUM}

A Revolução Norte-Americana e a promulgação da Constituição dos Estados Unidos da América deram forma ao movimento constitucionalista liberal, inaugurando um Estado de Direito pautado num regime democrático, federativo e republicano que garantiu direitos aos cidadãos na medida em que limitou a autoridade estatal. No entanto, seu caráter eminentemente liberal não se propôs a resolver os problemas de desigualdade social e política que afligiam a nação estadunidense, nem se propunha a uma universalização de seus ideais, tendo como objetivo organizar e dar forma a uma nação cuja independência havia sido, então, conquistada.

Numa França composta em grande parte por camponeses situados à margem de um sistema feudal estamentário, que se mostrava ineficiente diante da complexidade e da imensa 
gama de problemas sociais da época - os ideais oriundos do movimento iluminista começaram a ser difundidos pela burguesia e a questionar os paradigmas de outrora ${ }^{1}$.

Conforme ilustrado por $\mathrm{BAGGIO}^{2}$, em que pese as origens vinculadas à doutrina cristã, a fraternidade adquire uma dimensão política somente a partir da Revolução Francesa e da interação com dois outros princípios que comporiam a trilogia revolucionária: liberdade e igualdade. Entretanto, a fraternidade não teve a mesma sorte dos demais princípios revolucionários, de sorte que o pensamento democrático pós-revolucionário manteve-se em silêncio para com a fraternidade ${ }^{3}$.

Porém, conforme se demonstra neste artigo, com o avanço da Modernidade o próprio ideal democrático acabou por trair suas raízes revolucionárias e por relegar a contrapartida de participação a um plano marginal perante a dimensão representativa. Da mesma sorte, a Sociedade, ao invés de obter o status de sujeito coletivo de direito acabaria diluída entre as esferas pública e privada, e além do mais, sendo silenciada pelo ideário burguês pósrevolucionário.

Não se trata de mera coincidência, mas de um mesmo projeto de Modernidade de caráter individualista, monista e autocrático que visava assegurar prioritariamente interesses dos meios de produção e do capital em relação às grandes massas marginalizadas e situadas a parte dos espaços de representação política. Era uma estratégia de dominação.

Nesse sentido, apesar da ruptura com o sistema feudal e com o absolutismo, a Monarquia Parlamentar instaurada pela Constituição Francesa de 1791 rompeu com as pretensões democráticas universalistas da Revolução Francesa ao estabelecer um sistema eleitoral censitário, que provocou descontentamento do povo, haja vista que apenas realizou uma transição de poder entre déspotas: “[...] o poder não estava mais na monarquia absoluta, mas sim, no despotismo dos homens do dinheiro [...]"4. Os verdadeiros intentos da burguesia revolucionária começaram a transparecer na medida em que a igualdade foi assegurada apenas sob uma perspectiva formal, no que tange ao tratamento perante a lei, de modo que a posse das

\footnotetext{
${ }^{1}$ OLIVEIRA, Olga Maria Boschi Aguiar de. O Princípio da Fraternidade no Âmbito das Revoluções Moderna e Contemporânea. In: OLIVEIRA, Olga Maria Boschi Aguiar de; VERONESE, Josiane Rose Petry (Org.). Direitos na Pós-Modernidade: a fraternidade em questão. Florianópolis: Boiteux, 2011. p.102

2 BAGGIO, Antonio Maria. A Redescoberta da Fraternidade na Época do "Terceiro 1789". In: BAGGIO, Antonio Maria (Org.). O Princípio Esquecido: a fraternidade na reflexão atual das ciências políticas. v.1. São Paulo: Cidade Nova, 2008. p.08

${ }^{3}$ BAGGIO. Ibid. p.09

${ }^{4}$ OLIVEIRA. op. cit. p.92
} 
ISSN 1981-3694

(DOI): $10.5902 / 1981369415754$

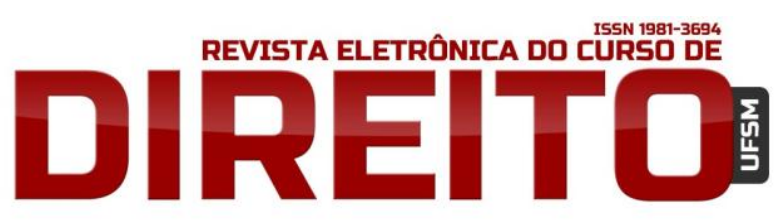

A FRATERNIDADE COMO PRINCÍPIO ÉTICO NECESSÁRIO PARA UMA NOVA PRÁXIS COLETIVA E EMANCIPATÓRIA EM DIREITOS HUMANOS

terras continuava nas mãos da burguesia e da aristocracia, deixando de lado os camponeses e assim persistindo os problemas de desigualdade no aspecto material ${ }^{5}$.

$\mathrm{Na}$ verdade os burgueses e aristocratas não visavam uma melhor distribuição da propriedade, mas tão somente garanti-la em relação ao Estado e promover o livre mercado, mediante o controle dos espaços de representação política conquistados com a Revolução Francesa e não partilhados posteriormente com o povo. Atitude, pois, que já indicava, em si, uma postura não fraternal para o período pós-revolucionário.

Nesse contexto, a própria organização do clube dos jacobinos e do clube dos girondinos evidenciava o cisma que a modernidade promoveria entre os primados do Estado, o Direito e a Comunidade. 0 clube dos jacobinos, por mais que comportasse algumas personalidades com convicções democráticas, como o próprio Robespierre, era de caráter eminentemente burguês: só admitia cidadãos considerados ativos e tratava suas deliberações diretamente junto ao Estado através da Assembleia Nacional ${ }^{6}$. Por outro lado, o clube dos Cordeliers - que posteriormente foi vencido pelos jacobinos - acolhia cidadãos de toda sorte e classe, executando um trabalho muito mais fraterno, diretamente na comunidade ${ }^{7}$.

A própria matriz democrática dos jacobinos acaba por se extinguir mais adiante, o que transparece do próprio destino de Robespierre, o qual, apesar do despotismo, enfrentou a alta burguesia ao dar maior assistência aos pobres e estender-lhes os direitos políticos na Constituição Francesa de 1793, para logo em seguida ser preso e guilhotinado, sem julgamento ${ }^{8}$. Com a morte de Robespierre, a Convenção Nacional passa a ser controlada pelos políticos que representam a alta burguesia, e que firmam seu controle sobre os espaços de representação política, até Napoleão Bonaparte; que em 1804, Imperador, põe termo a um processo revolucionário que há muito havia perdido seu espírito fraterno?.

O caráter pluralista e fraterno de um direito que não derivaria de um soberano, mas que se fundaria na vontade geral dos cidadãos foi à derrocada através das reformas administrativas e codificações promovidas por Napoleão Bonaparte a partir de 1799, estas que representaram o fim das fontes plurais de direito e das várias formas de jurisdição, consagrando o abandono da

\footnotetext{
${ }^{5}$ OLIVEIRA. ibid. p.94-95

${ }^{6}$ BAGGIO. Op. Cit. p.30

${ }^{7}$ BAGGIO. Ibid.

${ }^{8}$ OLIVEIRA. op. cit. p.96-97

${ }^{9}$ OLIVEIRA. ibid. p.97-98
} 
ISSN 1981-3694

(DOI): $10.5902 / 1981369415754$

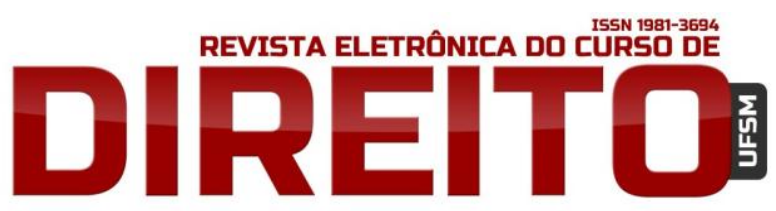

A FRATERNIDADE COMO PRINCÍPIO ÉTICO NECESSÁRIO PARA UMA NOVA PRÁXIS COLETIVA E EMANCIPATÓRIA EM DIREITOS HUMANOS

fraternidade enquanto categoria política na medida em que suas raízes cristãs foram identificadas e consideradas incompatíveis com o a concepção republicana de fraternidade ${ }^{10}$.

A partir de então, "a soberania do povo retira-se para o anonimato de processos democráticos e para a implementação jurídica de seus pressupostos comunicativos pretensiosos para fazer-se valer como poder produzido comunicativamente"11. Em outras palavras, a soberania popular passou a ser enclausurada por um modelo de democracia representativa imposta pelo Estado e que se fazia valer como produção coletivo-comunicativa, quando na verdade se tratava de um sistema fechado e elitista. A visão liberal supostamente buscou superar a separação entre Estado e sociedade através de um processo democrático representativo que teria como função única a legitimação do exercício do poder político, ao invés de primar por um processo participativo que materialize a vontade e soberania popular ${ }^{12}$.

Segundo SANTOS ${ }^{13}$, o projeto da modernidade se caracterizou pela busca do equilíbrio entre regulação e emancipação; os quais constituíram os pressupostos que serviram de base para a transformação da sociedade pré-moderna; cada qual sustentado por determinados princípios e racionalidades: o pilar da regulação centrado nos princípios do Estado, do mercado e da comunidade, ao passo que a emancipação na articulação entre as racionalidades moral-prática do direito moderno, ou seja, o cognitivo-experimental da ciência e da técnica modernas, e o estético-expressivo das artes e da literatura modernas. A partir de tais prerrogativas, o equilíbrio objetivado entre regulação e emancipação se obteria através da harmonização e relação dinâmica entre os princípios e racionalidades que compõem os pilares da regulação e emancipação ${ }^{14}$.

Entretanto, tal harmonização jamais foi alcançada. Por um lado, no que concerne à emancipação, a racionalidade cognitivo-experimental da ciência e da técnica desenvolveu-se em detrimento das demais racionalidades e acabou por colonizá-las, como no caso do Direito, onde a reflexão filosófica, sociológica e política foram reduzidas à ciência jurídica dogmática, dando margem a hegemonia epistemológica do positivismo, e, concomitantemente, ao monismo

\footnotetext{
10 OLIVEIRA. p.50; 99-100

11 HABERMAS, Jurgen. Direito e Democracia: entre facticidade e validade. Vol2. Rio de Janeiro: Tempo Brasileiro, 1997. p.24

12 HABERMAS. p.20-22

13 SANTOS, Boaventura de Souza. Pela Mão de Alice: o social e o político na pós-modernidade. 7.ed. São Paulo: Cortez, 2000. p.236

${ }^{14}$ SANTOS. ibid.
} 
político-jurídico ${ }^{15}$. Ademais, no âmbito da regulação, ocorreu um desenvolvimento hipertrofiado do mercado em detrimento do Estado e de ambos em detrimento da comunidade ${ }^{16}$.

O projeto da modernidade diluiu a soberania popular em processos eminentemente representativos de alto teor burocrático e tecnocrático, ocultando o aspecto "democrático da democracia" e promovendo a colonização da comunidade pelo Estado e o Mercado. Ora, considerando que a fraternidade radica-se na comunidade mediante processos participativos de caráter intersubjetivo, é possível afirmar que o dito “esquecimento" do princípio da fraternidade não foi mero desleixo do contexto pós-revolucionário, mas um artifício empregado para implementar o projeto de modernidade liberal-burguês que coincide com a supressão da democracia direta pela democracia indireta. De fato, para que uma democracia de cunho participativo possa ser considerada legítima, deve ter como pressuposto básico da sua práxis a Fraternidade.

Mas, a ruptura realizada pelo projeto de modernidade liberal-burguês não se limita a uma cisão com o aspecto fraterno das dinâmicas políticas e jurídicas. Para se tornar hegemônico, foi necessário afetar também o regime de tutela de bens assim como a titularidade destes bens, ao não reconhecer a Sociedade como sujeito coletivo de Direito. Nas palavras de PILATI ${ }^{17}$ :

0 jurídico na Modernidade, pois, não consagra o coletivo como bem autônomo, mas o dilui nos meandros do ordenamento. Em benefício do privado, desclassifica o coletivo na substância. Proclama-o como direito, mas the dá a forma jurídica de dever. Negando-lhe autonomia jurídica como bem, despersonaliza-o na esfera do sujeito, suprimindo a participação efetiva da Sociedade; sonega-lhe a tutela específica de processo coletivo - para relegá-lo ao faz-de-conta de uma segurança jurídica praticamente nula por ineficaz e inoperante.

O coletivo foi diluído entre o público estatal e o privado individual, da mesma forma e no mesmo momento em que a fraternidade foi renegada em favor dos princípios da liberdade e igualdade, que foram impulsionados e moldaram visões antagônicas de mundo. 0 fato de ambas essas rupturas ocorrerem no contexto pós-revolucionário revela uma estratégia de consolidação do projeto de modernidade, dentro do qual as dinâmicas fraternas de cunho participativo não atendem aos interesses de manter o domínio do poder político e econômico.

\footnotetext{
${ }^{15}$ SANTOS. ibid.

${ }^{16}$ SANTOS. ibid. p.237

17 PILATI, José Isaac. Propriedade e Função Social na Pós-Modernidade. Rio de Janeiro: Lumen Juris, 2011. p.33
} 
A teoria liberal reduziu o exercício da cidadania ao voto, de modo que qualquer outra forma de participação política é excluída ou desencorajada, ao passo que a democracia representativa perdeu o contato com os anseios dos representados, tornando-se refém dos interesses dos grandes cartéis industriais e fazendo com que os cidadãos tornem-se alheios à representação política ${ }^{18}$. Nesse sentido, a Modernidade tem promovido uma marginalização do princípio rousseauniano da comunidade, uma vez que este não deve fundar-se numa relação política vertical cidadão-Estado, mas numa relação horizontal cidadão-cidadão de caráter político-participativo, ou seja, fraterna ${ }^{19}$.

Porém, tais tendências modernas levam ao que Enrique Dussel denomina "fetichização da política”, uma decorrência da inversão dos pressupostos de legitimidade do agir político. Sob o aspecto conceitual, DUSSEL ${ }^{20}$ classifica como potentia ${ }^{21}$ o poder político em si e que tem como origem e fundamento a comunidade ${ }^{22}$, ao passo que denomina potestas o poder político institucionalizado e organizado que é delegado pela potentia a determinados cidadãos para que representem a comunidade, o povo.

Tendo por base tais pressupostos, o fetichismo político está relacionado à absolutização da vontade dos representantes, que deixam de atuar em prol dos interesses da comunidade política, assim como de articular-se com esta, resultando numa cisão entre potestas (decorrente da maiestas popular) e potentia, vindo a primeira a fundar-se em si mesma e despotencializar a última, tornando esta uma massa passiva e sem voz que apenas recebe ordens de seus representantes ${ }^{23}$.

Ao promover a vontade política numa perspectiva vertical excludente e alheia aos anseios da comunidade, o paradigma moderno se mostra desafeto ao princípio da fraternidade, uma vez que esta opera num plano horizontal e dialógico que leva em consideração a

\footnotetext{
${ }^{18}$ SANTOS. op. cit. p.237-239

${ }^{19}$ SANTOS. ibid. p.239

20 DUSSEL, Enrique. 20 Teses de Política. São Paulo: Expressão popular, 2007. p.29-34

${ }^{21}$ Aristóteles define potentia como o princípio ou possibilidade de uma mudança qualquer, podendo esta mudança se dar em diversos sentidos: capacidade de realizar mudança em outra coisa ou em si mesmo; capacidade de sofrer uma mudança causada por outra coisa ou por si mesmo; capacidade de mudar ou ser mudado para melhor e não para pior; ou a capacidade de resistir a qualquer mudança. No Direito Romano: a maiestas (pode maior, soberania) está no populus; a potestas (direito de representar o povo por delegação legítima) está no magistrado eleito. Da potestas decorre o poder de imperium: de castigar, de dar ordens aos cidadãos.

${ }^{22}$ A CRFB vai de encontro com a concepção de DUSSEL na medida em que prevê que a soberania é oriunda do povo. Art. $1^{\circ}$ Parágrafo único: Todo poder emana do povo, que o exerce por meio de representantes eleitos ou diretamente, nos termos desta Constituição.
}

${ }^{23}$ DUSSEL. op. cit. p.44-45 
participação e o bem-estar do próximo. Assim, é de suma importância analisarem-se novos aspectos de produção da vida, que devem promover uma alternativa pós-moderna; que restabeleça a Sociedade em nova dinâmica; contemple o potencial da fraternidade.

\section{FRATERNIDADE, DEMOCRACIA E PARTICIPAÇÃO POPULAR: RUMO A UMA NOVA PRÁXIS COLETIVA DE CARÁTER INTERSUBJETIVO, DIALÓGICO E EMANCIPATÓRIO}

Pode-se observar do exposto, que ao longo da Modernidade a democracia participativa, direta, tem sido obscurecida pela outra face, a democracia representativa, indireta, a qual foi impulsionada pelo ideário liberal-burguês pós-revolucionário. Mas agora e à vista da imposição constitucional de participação (art. $1^{\circ}$, parág. único da CRFB), o que se constata são as tentativas do sistema de camuflar-se como uma produção coletiva, de caráter participativo ${ }^{24}$, em processos que de modo geral, apenas simulam a participação.

Cria-se uma ilusão de exercício de soberania popular, quando na verdade o que existe é o monopólio da soberania por uma parcela diminuta de grupos e indivíduos instituídos na dinâmica estatal $^{25}$. Não bastasse, há uma forte resistência às inovações que se proponham a expandir os canais de discussão e deliberação, como bem ilustra PILATI"26: "qualquer tentativa de participação efetiva da Sociedade, de retomada da soberania para o exercício dos direitos coletivos - é vista com desconfiança, pois o sistema tende a resolver as suas crises ao seu modo, sem participação, pela via estatal unilateral individualista”.

Dentro de tal contexto, mostra-se de suma importância resgatar a fraternidade enquanto princípio motriz de práticas democráticas de caráter coletivo-participativo, mediante a construção de um projeto pós-moderno.

\subsection{A Fraternidade como contributo para uma teoria contra-hegemônica dos direitos humanos.}

\footnotetext{
${ }^{24}$ PILATI. op. cit. p.31

${ }^{25}$ KOSELECK, Reinhart. Crítica e Crise: uma contribuição à patogênese do mundo burguês. Rio de Janeiro: Contraponto, 1999. p.144

${ }^{26}$ PILATI, José Isaac.ibid.
} 
Partindo desses pressupostos, SANTOS ${ }^{27}$ aponta o Estado-novíssimo-movimento-social como uma concepção de reforma do Estado que se justifica pelo fato de que, nem o princípio do Estado, nem o princípio da comunidade podem garantir, isoladamente, a sustentabilidade de arranjos político-jurídicos de natureza não mercantil indispensáveis para que a vida em sociedade não se converta num fascismo social. A sustentabilidade de tais garantias fundamentais seria possível, isso sim, mediante um Estado-novíssimo-movimento-social que promova a articulação entre os princípios do Estado e da comunidade, explorando os isomorfismos existentes entre ambos ${ }^{28}$.

O Estado-novíssimo-movimento-social visaria enaltecer a importância da participação popular, através de seus movimentos e organizações, na luta pelo controle democrático do Estado, de forma que o foco central dessa nova organização política seria a estabilização mínima das expectativas populares que o Estado liberal teria deixado de garantir ao perder o controle da regulação social para o mercado ${ }^{29}$.

Porém, a passagem para o Estado-novíssimo-movimento-social deve se dar com cautela para que o processo de transição democrática não resulte na passagem de um autoritarismo centralizado para um autoritarismo descentralizado ${ }^{30}$. Tal autoritarismo descentralizado consistiria num fascismo social, de natureza plural, e que pode se manifestar sob diversas formas, como a de um fascismo paraestatal, ou a de um fascismo financeiro ${ }^{31}$.

SANTOS $^{32}$ afirma que se faz necessário a construção de uma nova ação política democrática que, além de aliar os princípios do Estado e da comunidade, promova uma nova articulação entre democracia representativa e democracia participativa, para que assim seja possível garantir o potencial emancipatório de ambos os princípios do Estado e da comunidade frente aos fascismos sociais que cobiçam o espaço público estatal e não estatal ${ }^{33}$.

Por outro lado, a renovação democrática promovida pelo referido Estado-novíssimomovimento-social não deve recusar os princípios da democracia liberal, mas integrar estes a uma concepção mais abrangente que faça o uso contra-hegemônico da democracia representativa, primando assim por uma democracia mais ampla sem desqualificar a via eleitoral, porém

\footnotetext{
27 SANTOS, Boaventura de Souza. A Gramática do Tempo: para uma nova cultura jurídica. 2.ed. São Paulo: Cortez 2008. p. 363

${ }^{28}$ SANTOS. ibid.

${ }^{29}$ SANTOS. ibid. p.365

30 SANTOS. ibid. p.333

31 SANTOS. ibid. p.366

32 SANTOS. ibid.

${ }^{33}$ SANTOS. ibid.
} 
buscando critérios distintos de representação política que não se restrinjam apenas ao aspecto quantitativo proveniente do voto, mas visem articular tal fator quantitativo com o aspecto qualitativo proveniente de práticas sociais como aquelas protagonizadas pelos movimentos sociais ${ }^{34}$.

Dentro deste viés, Wolkmer ${ }^{35}$ aponta os "novos movimentos sociais" como uma nova categoria de sujeitos de direito capaz de lidar com a crise democrática e fraternal advinda da Modernidade. Segundo Wolkmer ${ }^{36}$, os novos movimentos sociais seriam "sujeitos coletivos transformadores, advindos de diversos estratos sociais e integrantes de uma prática política cotidiana com certo grau de institucionalização, imbuídos de princípios valorativos comuns e objetivando a realização de necessidades humanas fundamentais"; que mesmo diante de sua heterogeneidade compartilham determinados valores, principalmente: identidade e autonomia.

0 valor da identidade consiste no fato de os movimentos sociais serem defensores, representantes e promotores de determinados interesses de parcelas expressivas da sociedade, contrapondo-se a todas as formas de alienação e lutando para que, por meio de uma atitude fraterna baseada na comunhão de interesses e experiências, se tornem sujeitos de sua própria história $^{37}$. Por sua vez, o valor da autonomia manifesta-se na constituição de novas formas de ação, organização e consciência, tratando-se de um processo a ser construído coletivamente mediante a ação autônoma e independente dos sujeitos coletivos quando seus interesses não são atendidos ou reconhecidos pelas instâncias oficiais do Estado ${ }^{38}$.

É na esfera da comunidade suscitada por Santos que podemos identificar a fraternidade e as práticas que dela decorrem, de modo que é a própria fraternidade quem permite a formulação da ideia de povo, uma vez que é ela quem promove a identidade de setores sociais que antes viviam separados ${ }^{39}$. Da mesma forma, é a fraternidade que promove a ação autônoma destes novos movimentos sociais, sendo um ponto de partida para a conquista de novos direitos e para a consolidação de interesses coletivos, exigindo o compromisso e colaboração de todos ${ }^{40}$.

\footnotetext{
34 SANTOS, Boaventura de Souza. Pensar el Estado y laSociedad:desafíosactuales. Buenos Aires: Waldhunter, 2009. p.31-32

35 WOLKMER, Antonio Carlos. Pluralismo Jurídico: fundamentos de uma nova cultura no direito. São Paulo: Alfa Omega, 2001. p.122

${ }^{36}$ WOLKMER. ibid p.129

${ }^{37}$ WOLKMER. ibid. p.129-131

${ }^{38}$ WOLKMER.ibid. p.131-132

${ }^{39}$ BAGGIO. op. cit. p.31

${ }^{40}$ BAGGIO. ibid. p.54
} 
Nesse sentido é que se deve resgatar pelo menos uma parte da importante contribuição de Joaquín Herrera Flores ${ }^{41}$ para a construção de uma teoria dos direitos humanos de caráter contra-hegemônico dentro da qual a fraternidade figura como núcleo central para a promoção da dignidade e do acesso aos bens da vida.

Herrera Flores propõe uma nova perspectiva dos direitos humanos em que estes sejam identificados como processos institucionais e sociais que possibilitem a abertura e a consolidação de espaços de luta pela dignidade humana. 0 que tornariaos direitos humanos universais não seria seu mero reconhecimento jurídico, mas sim a construção de um marco de ação que permita a todos e a todas criar condições que garantam de um modo igualitário o acesso aos bens materiais e imateriais que fazem com que a vida seja digna de ser vivida, de modo que falar de direitos humanos consiste em falar da "abertura de processos de luta pela dignidade humana" ${ }^{42}$.

O autor supracitado enaltece uma concepção de direitos humanos que não caia numa dupla armadilha de concepções lógico/formais abstraídas dos contextos e das finalidades que deveriam assumir:

\begin{abstract}
Quando começamos a falar de direitos humanos destacando o conceito de "direitos", corremos o risco de "nos esquecer" dos conflitos e lutas que conduziram à existência de um determinado sistema de garantias dos resultados das lutas sociais e não a outro diferente. Falamos de direitos e parece que tal reconhecimento jurídico já solucionou todo o problema que envolve as situações de desigualdade ou de injustiça que as normas devem regular. Somente devemos nos preocupar com as garantias judiciais dos direitos, desprezando absolutamente que, atrás de todo edifício jurídico, se escondem sistemas de valores e processos de divisão do fazer humanos que privilegiam uns grupos e subordinam outros ${ }^{43}$.
\end{abstract}

Com base em tal preocupação, Herrera Flores $^{44}$ propõe uma teoria dos direitos humanos que não comece pelos "direitos"; numa perspectiva "a priori" e abstrata; mas que parta dos "bens" exigíveis para se viver com dignidade (educação, moradia, trabalho, cidadania, etc.), de modo que os direitos se consolidem após a luta pelo acesso aos bens; numa dimensão “ $a$ posteriori" e fraterna; de modo que as normas jurídicas se prestem a garantir o acesso a tais bens.

\footnotetext{
${ }^{41}$ HERRERA FLORES, Joaquín. A (Re)Invenção dos Direitos Humanos. Florianópolis: Boiteux, $2009 a$.

42 HERRERA FLORES. ibid. p.25-27

43 HERRERA FLORES, Joaquín. ibid. p.27

${ }^{44}$ HERRERA FLORES, Joaquín. ibid. p.34-35
} 
No entanto, Herrera Flores ${ }^{45}$ aponta cinco deveres básicos para que uma nova teoria dos direitos humanos; de caráter emancipatório e desenvolvia através de uma práxis coletiva e fraterna; seja possível:

1. O "reconhecimento" de que todos e todas, sem exceção, devemos ter a possibilidade de reagir culturalmente frente ao entorno de relações no qual vivemos.

2. O respeito como forma de conceber o reconhecimento como condição necessária, mas não suficiente, na hora de pôr em prática as lutas pela dignidade.

3. A reciprocidade como base para saber devolver o que tomamos dos outros para construir os nossos privilégios, seja dos outros seres humanos, seja da mesma natureza da qual dependemos para a reprodução primária da vida.

4. Assumir nossa responsabilidade na subordinação dos outros, e nossa responsabilidade de exigir responsabilidades aos que cometeram o saqueio e a destruição das condições de vida dos demais.

5. A redistribuição, ou seja, o estabelecimento de regras jurídicas e ações políticas e econômicas concretas que possibilitem a todos não somente satisfazer suas necessidades primárias, mas, além disso, a construção de uma dignidade humana não submetida aos processos depredatórios do sistema capitalista.

Tais pressupostos indicados pelo autor supracitado (reconhecimento, respeito, reciprocidade, responsabilidade e redistribuição) coincidem com o resgate de uma experiência fraterna que atua sob o mesmo plano horizontal defendido por Baggio ${ }^{46}$, uma vez exigem a formação de um processo coletivo não excludente no qual cada participante vele pela dignidade e o bem estar de seu semelhante.

A fraternidade seria o "conatus", a "potência humana de transformação e mudança em prol da dignidade" capaz de promover os direitos humanos como uma convenção coletiva político-jurídica de caráter provisório ${ }^{47}$ e antagônico ao paradigma da modernidade ocidental liberalista-individualista, de cunho excludente, eminentemente representativo, e que se observa como um processo já findo ${ }^{48}$.

Nas palavras do autor:

Sob nosso politizado conceito de fraternidade não se escondem propostas de tolerância abstratas, mas impulsos concretos de solidariedade e de emancipação que permitem a elevação de todas as classes domésticas ou civilmente subalternas à condição de sujeitos plenamente livres e iguais. [...] Em outros

\footnotetext{
${ }^{45}$ HERRERA FLORES, Joaquín. ibid. p.68

${ }^{46}$ BAGGIO. op. cit. p.22

${ }^{47}$ Provisório por admitir sua renovação e aperfeiçoamento na medida em que se desenvolvem os processos de luta pelo acesso aos bens da vida.

${ }^{48}$ HERRERA FLORES, Joaquín. Teoria Crítica dos Direitos Humanos: os direitos humanos como produtos culturais. Rio de Janeiro: Lumen Juris, 2009b. p.192-193
} 
termos, especificamos os direitos a partir de uma perspectiva pragmática e de forte conteúdo social. Com isso, pretendemos complementar e ampliar o conceito de igualdade formal aos aspectos materiais e concretos que permitem a colocação em prática da liberdade positiva e da fraternidade emancipadora que subjaz ao conceito de igualdade material. Os direitos não vão funcionar por si mesmos, nem vão ser implementados unicamente a partir do, por outro lado necessário, trabalho jurídico ${ }^{49}$.

Honneth $^{50}$ também aponta a existência de um abismo entre a filosofia jurídica moderna e a práxis política, uma vez que os princípios filosóficos foram formulados num nível de abstração que impossibilita absorver deles uma orientação concreta para uma ação política efetiva. 0 autor supracitado indica três elementos comuns às teorias da justiça desenvolvidas pela Modernidade e que fazem jus a uma transposição: o paradigma da distribuição; o procedimentalismo; e o Estado de Direito.

Segundo as teorias modernas, um indivíduo é tanto mais livre quanto menor forem as interferências de outros sujeitos em sua vida, ou seja, quanto menos depender de seus semelhantes, de modo que os vínculos sociais poderiam ser considerados limites à liberdade individual $^{51}$. Sob tal perspectiva, não se deve atribuir aos membros da Sociedade a responsabilidade pela distribuição dos bens da vida, cabendo ao Estado tal tarefa, de modo que o que não estiver ao alcance do Estado deve ficar fora da esfera do Direito ${ }^{52}$.

Contrariando as teorias tradicionais, Honneth ${ }^{53}$ afirma que a liberdade só pode ser alcançada através do reconhecimento do sujeito por outras pessoas, visto que a autonomia necessita do reconhecimento recíproco entre os sujeitos, dependendo, portanto, da cooperação entre estes, ou seja: a autonomia não se firma no individualismo, mas numa dimensão relacional. Da mesma forma, o procedimentalismo e o Estado de Direito já não se adéquam às exigências de um paradigma pós-moderno, pois a fixação na figura do Estado e no aspecto formal-burocrático acaba reduzindo substancialmente nossa concepção de justiça ${ }^{54}$.

Nesse sentido, Honneth ${ }^{55}$ propõe a substituição dos elementos tradicionais presentes nas teorias da justiça atuais por novos pressupostos:

\footnotetext{
${ }^{49}$ HERRERA FLORES. ibid. p.193-194

50 HONNETH, Axel. A Textura da Justiça. Civitas. Porto Algre. v. 9. n. 3. p. 345-368, set.-dez. 2009 a.

p. 347

51 HONNETH. ibid. p.348-349

${ }^{52}$ HONNETH. ibid. p. 351

53 HONNETH. ibid. p.353-354

${ }^{54}$ HONNETH. ibid. p. 359

${ }^{55}$ HONNETH. ibid. p.360
} 
ISSN 1981-3694

(DOI): $10.5902 / 1981369415754$

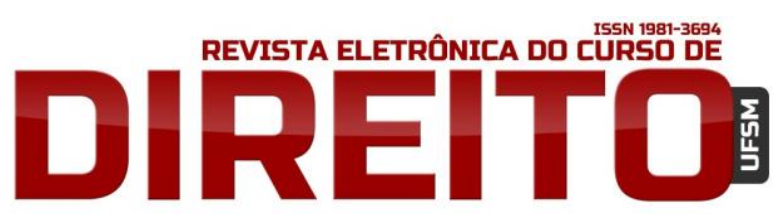

A FRATERNIDADE COMO PRINCÍPIO ÉTICO NECESSÁRIO PARA UMA NOVA PRÁXIS COLETIVA E EMANCIPATÓRIA EM DIREITOS HUMANOS

1. Substituir o esquema distributivo por relações de reconhecimento intersubjetivas que contemplem todos os sujeitos.

2. Substituir o procedimentalismo fictício por uma reconstrução normativa que revele as normas morais presentes nas relações de reconhecimento.

3. Complementar a atividade reguladora do Estado de Direito através de uma política descentralizadora que contemple organizações não estatais.

Os princípios da justiça devem passar por uma reconfiguração na qual resultem de uma formação comum da vontade que só se concretiza na cooperação entre sujeitos, ou seja, mediante uma práxis fraterna e intersubjetiva que promova a autonomia dos sujeitos através do reconhecimento recíproco entre estes mesmos indivíduos ${ }^{56}$. Em outras palavras: o ser humano é tão livre quanto mais forte forem os elos de reconhecimento e respeito mútuo por seus semelhantes.

0 pensamento Moderno parte de um atomismo que se caracteriza por pressupor a existência de indivíduos isolados uns dos outros, dentro do qual a noção de "comunidade" se reduz a uma associação de pessoas, isto é, a um aglomerado de sujeitos individualmente isolados uns dos outros ${ }^{57}$. Nesse viés, por se prender a concepções atomísticas, o paradigma moderno não está apto a desenvolver um novo arquétipo de comunidade, sendo necessário o desenvolvimento de um novo sistema de categorias que prime por um movimento de reconhecimento que consista num processo de etapas de reconciliação e conflito ao mesmo tempo, dentro do qual os indivíduos não de contrapõem uns aos outros como agentes egocêntricos, mas como membros de uma totalidade ética ${ }^{58}$.

\subsection{A Fraternidade como princípio estruturante de uma nova dimensão de direitos fundamentais.}

Do que foi exposto na subseção anterior, é possível identificar a fraternidade como uma ação política democrática capaz de reaproximar os princípios do Estado e da Comunidade e de promover uma nova perspectiva de direitos humanos que atue sob um viés pragmático e avesso a simples abstrações jurídicas forjadas por mecânicas de caráter exclusivamente representativo, impostas de cima para baixo, passando a primar por processos participativos que tenham como fim último o acesso aos bens da vida e sua distribuição equânime.

\footnotetext{
${ }^{56}$ HONNETH. ibid. p.348

${ }^{57}$ HONNETH, Axel. Luta por Reconhecimento: a gramática moral dos conflitos sociais. 2.ed. São Paulo: 34, 2009b. p.39-40

${ }^{58}$ HONNETH. ibid. p.47-57
} 
É a fraternidade que também promove a identidade e autonomia dos novos sujeitos coletivos emergentes e é essa mesma fraternidade, que imbuída dos deveres de reconhecimento, respeito, reciprocidade, responsabilidade e redistribuição, é capaz de impedir que o processo de transição democrática ora almejado resulte na passagem de um autoritarismo centralizado para um autoritarismo descentralizado.

Disso se extrai que, mais do que um princípio ou uma regra, a fraternidade é uma experiência ${ }^{59}$, e como tal não deve ser imposta de cima para baixo, numa perspectiva vertical, mas sim a partir de um processo intersubjetivo dialógico que se desenvolva num plano horizontal que flua de baixo para cima.

Ademais, apesar de se radicar no princípio da comunidade e servir de fundamento para os subprincípios da identidade, autonomia e participação, a fraternidade necessita de um aparato jurídico capaz de lhe dar forma e instrumentalidade, o que é possível através do reconhecimento de direitos coletivos de titularidade da Sociedade enquanto sujeito de direito e exercida por esta mediante dinâmicas processuais de cunho coletivo-deliberativo.

Como bem ilustra Baggio ${ }^{60}$, "os princípios da trilogia francesa poderiam ser comparados às pernas de uma mesa: são necessárias todas as três para que ela se sustente”. Apesar de a Modernidade ter enfatizado a liberdade e a igualdade em detrimento da fraternidade, e, concomitantemente, ter enaltecido os aspectos individualistas e autocráticos dos direitos humanos, tal problemática não será resolvida por meio de uma oposição aos princípios da liberdade e da igualdade, mas sim através de uma articulação entre tais pressupostos e a fraternidade ${ }^{61}$.

O termo "participação" pode ser considerado uma variação da fraternidade bem como um dos campos de experimentação mais relevantes para o exercício desta, visto que a fraternidade pode ser considerada uma categoria de pensamento essencial para uma práxis democrática de cunho participativo e emancipatório ${ }^{62}$. É justamente dentro do campo da participação que se promoverá a articulação entre os princípios da trilogia francesa. Mas que

\footnotetext{
59 Partindo dos pressupostos de Antonio Martia Baggio, antes de tudo, a fraternidade é algo para ser vivido, porque somente vivendo-a ela pode ser compreendida.

${ }^{60}$ BAGGIO. op. cit. p. 18

61 TOSI, Giuseppe. A Fraternidade é uma Categoria Política? In: BAGGIO, Antonio Maria (Org.). O Princípio Esquecido: exigências, recursos e definições da fraternidade na política. Vol. 02. São Paulo: Cidade Nova, 2009. p.58-59

62 BAGGIO, Antonio Maria. A Inteligência Fraterna: democracia e participação na era dos fragmentos. In: BAGGIO, Antonio Maria (Org.). O Princípio Esquecido: exigências, recursos e definições da fraternidade na política. Vol. 02. São Paulo: Cidade Nova, 2009. p.85-86
} 
participação seria essa? Baggio ${ }^{63}$ indica que deve se tratar de uma participação de caráter "forte" que resulte na superação da racionalidade instrumental das sociedades ocidentais contemporâneas e possibilite a passagem de um procedimento de deliberação exclusivamente individual para o de uma deliberação intersubjetiva capaz de instaurar uma ética compartilhada que resulte no reconhecimento de um bem comum da Sociedade.

Nas palavras de Baggio ${ }^{64}$ :

O conceito de participação, assim entendido, indica um vínculo que leva a reconhecer a existência de um bem comum da sociedade à qual se pertence, um bem relevante para a vida pessoal do sujeito participante e que, para ser alcançado, exige um empenho de participação de caráter voluntário que vai além daquilo a que se é obrigado por lei.

Nesse sentido, uma participação forte implicaria um processo deliberativo não mais individual, mas comum, que consista não apenas na partilha de um espaço físico, mas interior, cujo objeto de deliberação é o bem comum da Sociedade, ou um aspecto dele ${ }^{65}$.

Entretanto, não basta o reconhecimento da existência de um princípio de fraternidade capaz de fundamentar e animar práticas participativas e radicadas no seio da Sociedade, também se faz necessário instrumentalizar a fraternidade e a nova dimensão de Sociedade que esta propõe. Nesse sentido, a proposta de Pilati indica uma nova práxis jurídica fundada em direitos coletivos de natureza constitucional, de titularidade da Sociedade enquanto sujeito de direito propriamente dito, e tutelados por um processo coletivo participativo: tanto no campo do exercício como da tutela dos direitos coletivos.

Pilati $^{66}$ estrutura seu pensamento a partir do que chamada de complexidade pósmoderna, uma etapa de transição paradigmática que importa em preservar tudo aquilo que melhor se obteve da Modernidade até o momento; inclusive os princípios da trilogia francesa e as práticas democráticas dela oriundas; e reestruturar tais conquistas a fim de restabelecer o Direito como instrumento de reconstrução a partir do conflito. Não se trata de uma ruptura, mas de uma etapa de transição paradigmática, ou seja, da passagem de uma Modernidade centrada no Estado como ente superior, separado da Sociedade e legitimado por processos burocrático-

\footnotetext{
${ }^{63}$ BAGGIO. ibid. p.89

${ }^{64}$ BAGGIO. ibid. p.92

${ }^{65}$ BAGGIO. ibid. p.96-98

66 PILATI, José Isaac. Teoria Pós-Moderna do Direito: paradigma como método e soberania partilhada como elemento fundamental. 2014. p.02
} 
representativos, para uma Pós-Modernidade fundada no coletivo não estatal e no conceito de soberania compartilhada ${ }^{67}$.

Por ser desenvolvido para resolver problemas entre indivíduos, o Direito da Modernidade prima pela simplicidade, apegando-se a um sistema abstrato de leis estatais que delega ao Estado e assim relega a uma tutela "de segunda categoria” as questões coletivas e de interesse geral, deixando a Sociedade fora da resolução dos conflitos coletivos ${ }^{68}$.

A Teoria Pós-Moderna proposta por Pilati ${ }^{69}$ visa uma nova classificação de bens, sujeitos e processos: bens coletivos, pertencentes à Sociedade, objetos de soberania compartilhada, e tutelados por um devido processo legal participativo que é exercido numa dimensão de iure constituendo; em que a solução coletiva se constrói a cada situação, no caso concreto. Trata-se de uma visão do fenômeno jurídico voltada para a obtenção do justo e não apenas para a interpretação da lei, recuperando o conflito em seu sentido positivo: “como um lugar privilegiado de mediação e construção, com a presença de Estado, indivíduo e Sociedade, num foro participativo" 70 .

A Sociedade pós-moderna não se trata apenas de um conjunto de indivíduos, mas é sujeito de Direito, retorna repersonalizada e reabilitada para o exercício de uma tutela coletiva, redesenhando a República Participativa em três esferas: Estado, Indivíduo e Sociedade ${ }^{71}$. Tratase, enfim, e uma abordagem que parte de uma revisão das fontes romanas clássicas de democracia direta: "res publica romanorum".

Numa dimensão próxima da Teoria Pós-Moderna, Baggio ${ }^{72}$ identifica a "humanidade" como o sujeito ao qual a fraternidade está associada:

A fraternidade, no entanto, no decorrer da história, foi adquirindo um significado universal, chegando a identificar o sujeito ao qual ela pode referir-se plenamente: o sujeito "humanidade" - comunidade de comunidades -, o único que garante a completa expressão também aos outros dois princípios universais, a liberdade e a igualdade.

A partir da ideia de humanidade enquanto uma comunidade de comunidades pode-se vincular à Sociedade - enquanto sujeito de direito de dimensões coletivas - a titularidade e o exercício da fraternidade, a qual pode suscitar o reconhecimento de uma nova dimensão de

\footnotetext{
${ }^{67}$ PILATI. ibid. p.04

${ }^{68}$ PILATI. ibid. p.07

${ }^{69}$ PILATI. ibid. p.05-06

${ }^{70}$ PILATI. ibid. p.07

${ }^{71}$ PILATI. op. cit. p. 122

${ }^{72}$ BAGGIO. op. cit. p.21
} 
ISSN 1981-3694

(DOI): $10.5902 / 1981369415754$

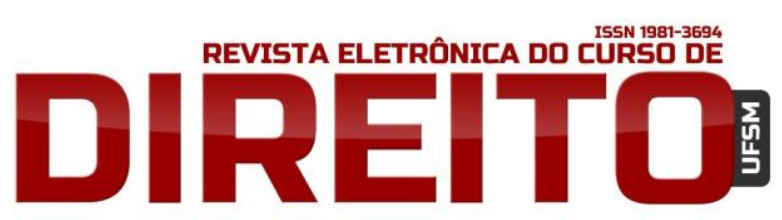

A FRATERNIDADE COMO PRINCÍPIO ÉTICO NECESSÁRIO

PARA UMA NOVA PRÁXIS COLETIVA E EMANCIPATÓRIA EM DIREITOS HUMANOS

direitos fundamentais, embasados num principium fraternitas ${ }^{73}$, o que exige uma conduta de caráter participativo fundada na alteridade: direitos coletivos de natureza extrapatrimonial. Essa nova dimensão de direitos versaria sobre o que Pilati ${ }^{74}$ denomina como "bens coletivos constitucionais", bens autônomos de propriedade coletiva e com titular coletivo - a Sociedade cujo exercício e tutela não dependem do voluntarismo estatal, mas deve realizar-se mediante um processo participativo inclusivo e avesso às dinâmicas modernas de caráter excludente.

Do ponto de vista do Direito de propriedade, são propriedades especiais que possuem em comum as seguintes características: raiz constitucional, lei própria órgão próprio de supervisão com poderes executivos e função social ${ }^{75}$. E entre elas a propriedade extrapatrimonial coletiva, como o direito ao meio ambiente equilibrado. Na propriedade dominial moderna o proprietário atua livremente dentro daquilo que a lei the permite, já no paradigma pós-moderno esse mesmo proprietário deve conviver com propriedades coletivas regidas pelo marco participativo e exercidas de acordo com sua função social; a qual não se limita a mera solidariedade social, nem se reduz a um significado vazio, mas é reforçada pelo dever de responsabilidade na tutela de tais bens, o qual é oriundo dos elos de fraternidade que compõem a Sociedade ${ }^{76}$.

Todavia, a Teoria Pós-Moderna não dispensa a atuação de autoridades representativas na tutela coletiva de tais bens, ou seja, desse condomínio de inclusão. Dentro do processo judicial participativo, por exemplo, o juiz deve adotar uma postura condizente com a realidade do bem envolvido, conduzindo a deliberação e homologando a decisão, ao passo que cabe à Sociedade em audiência pública ou outras dinâmicas de teor coletivo-participativo - deliberar sobre o conteúdo de tais demandas. Em suma, no paradigma pós-moderno a autoridade representativa atua dentro da dimensão formal, ao passo que a Sociedade responde pela dimensão material, numa perspectiva de ágora e sob um viés fraterno que exige uma postura de co-responsabilidade na tutela dos bens coletivos constitucionais.

É a fraternidade que permite a formação de um espírito público capaz de criar a unidade entre os cidadãos e promover a Sociedade como um novo sujeito de Direito. Porém, deve se tomar cuidado para que os processos de deliberação coletiva decorrentes dessa nova dimensão

\footnotetext{
73 Terminologia utilizada por Rossetto (2013) para indicar uma práxis histórica, de tempo, contexto, espaço e realidade social, qual seja, uma modelização substantiva de fraternidade, a qual seria exercida por uma dinâmica, uma prática de tratamento dos conflitos, ações e situações sociais, equivalentes a um sistema constitucional cooperativo.
}

${ }^{74}$ PILATI. op. cit. p.08

${ }^{75}$ PILATI. ibid. p.10-11

${ }^{76}$ PILATI. ibid. p.14 
ISSN 1981-3694

(DOI): $10.5902 / 1981369415754$

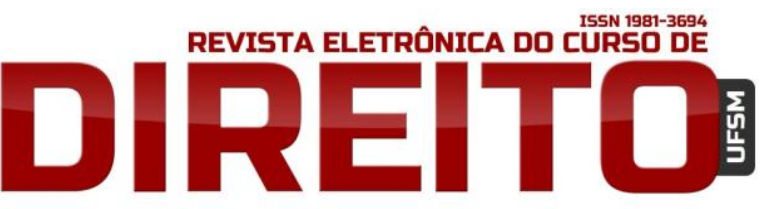

A FRATERNIDADE COMO PRINCÍPIO ÉTICO NECESSÁRIO PARA UMA NOVA PRÁXIS COLETIVA E EMANCIPATÓRIA EM DIREITOS HUMANOS

de direitos encabeçada pela Sociedade não resulte naquilo que Tocqueville ${ }^{77}$ chama de "ditadura das maiorias", ou seja, no exercício de processos democráticos sem levar em consideração uma perspectiva de alteridade, sem dialogar com as minorias. Daí, com efeito, a complexidade pósmoderna e a necessidade de se criarem e aperfeiçoarem os sistemas de exercício e tutela dos direitos na contemporaneidade.

Os processos de deliberação a serem desenvolvidos por essa nova dimensão de direitos fundamentais fundamentada na fraternidade devem adotar um caráter intersubjetivo, pois o objeto de deliberação de tais demandas é um bem compartilhado, comum, o que faz necessário interagir, dialogar e compreender os outros e suas diversidades oriundas de uma Sociedade culturalmente não homogenia. A redefinição da categoria de alteridade seria o grande desafio da fraternidade ao constituir uma nova práxis democrática de teor pós-moderno, o que somente será superado na medida em que desenvolvermos um movimento de reconhecimento intersubjetivo pautado pelos deveres de respeito, responsabilidade, reciprocidade e redistribuição da justiça e dos bens jurídicos.

\section{CONCLUSÃO}

Procurou-se enriquecer a discussão em torno da categoria Fraternidade como pressuposto fundamental para o desenvolvimento de uma práxis pós-moderna em direitos humanos. Retornando ao momento histórico em que liberdade e igualdade erigiram o ideário moderno, flagrou-se a ruptura liberal com a Fraternidade; e bem assim o seu retorno pós-moderno dos dias atuais, de cunho coletivo, participativo e emancipatório. Verifica-se que os autores citados caminham na mesma direção, mas os textos não se mostram, no conjunto, definitivos.

Até mesmo porque, e essa é a conclusão, a dimensão coletiva em que retorna ao debate a Fraternidade é uma dimensão de iure constituendo. Com outras palavras, a participação solidária e inclusiva deverá desenhar o futuro à base dos problemas concretos, o que bem atesta, de certa forma e sem dúvida, a evocação da casuística romana de democracia direta, aos tempos da res publica res Populi.

No entanto, é inviável contemplar num único artigo científico toda a magnitude de uma nova proposta tendente a recepcionar a fraternidade num viés jurídico-político, como princípio

77 TOCQUEVILLE, Alexis de. A Democracia na América: leis e costumes. 2.ed. São Paulo: Martins Fontes, 2005. 
estruturante de uma dimensão de direitos fundamentais de natureza coletiva constitucional cujo exercício se dá mediante dinâmicas de cunho participativo.

Para se projetar uma alternativa pós-moderna no âmbito do Direito se faz necessário uma análise e releitura das instituições jurídicas modernas a fim de apontar os ônus e os bônus da Modernidade jurídica, resgatando seus aspectos positivos, preenchendo lacunas e reestruturando suas nuances, sobretudo as instituições que o paradigma da Pós-Modernidade venha apontar como insuficientes ou inadequadas.

Tendo em vista tais preocupações, o presente artigo trata-se de um mero ensaio de uma proposta pós-moderna a ser trabalhada em nível de doutoramento com a devida atenção e detalhe, restando apenas a provocação inicial lançada ao leitor, a qual será aguçada posteriormente nas pesquisas vindouras.

\section{REFERÊNCIAS}

BAGGIO, Antonio Maria. A Redescoberta da Fraternidade na Época do "Terceiro 1789". In: BAGGIO, Antonio Maria (Org.). O Princípio Esquecido: a fraternidade na reflexão atual das ciências políticas. v.1. São Paulo: Cidade Nova, 2008.

. A Inteligência Fraterna: democracia e participação na era dos fragmentos. In: BAGGIO, Antonio Maria (Org.). O Princípio Esquecido: exigências, recursos e definições da fraternidade na política. Vol. 02. São Paulo: Cidade Nova, 2009.

DUSSEL, Enrique. 20 Teses de Política. São Paulo: Expressão popular, 2007.

HABERMAS, Jurgen. Direito e Democracia: entre facticidade e validade. Vol2. Rio de Janeiro: Tempo Brasileiro, 1997.

HERRERA FLORES, Joaquín. A (Re)Invenção dos Direitos Humanos. Florianópolis: Boiteux, 2009a.

- Teoria Crítica dos Direitos Humanos: os direitos humanos como produtos culturais. Rio de Janeiro: Lumen Juris, 2009b.

HONNETH, Axel. A Textura da Justiça. Civitas. Porto Algre. v. 9. n. 3. p. 345-368, set.-dez. 2009a.

2009b.

Luta por Reconhecimento: a gramática moral dos conflitos sociais. 2.ed. São Paulo: 34,

KOSELECK, Reinhart. Crítica e Crise: uma contribuição à patogênese do mundo burguês. Rio de Janeiro: Contraponto, 1999. 
OLIVEIRA, Olga Maria Boschi Aguiar de. O Princípio da Fraternidade no Âmbito das Revoluções Moderna e Contemporânea. In: OLIVEIRA, Olga Maria Boschi Aguiar de; VERONESE, Josiane Rose Petry (Org.). Direitos na Pós-Modernidade: a fraternidade em questão. Florianópolis: Boiteux, 2011.

PILATI, José Isaac. Propriedade e Função Social na Pós-Modernidade. Rio de Janeiro: Lumen Juris, 2011.

- Teoria Pós-Moderna do Direito: paradigma como método e soberania partilhada como elemento fundamental. 2014.Digit.

ROSSETTO, Geralda Magella de Faria. PrincipiumFraternitas: contributo a metodologia interpretativa na perspectiva da proporcionalidade. In: VERONOSE, Josiane; OLIVEIRA, Olga Maria B. Aguiar de. Direitos na Pós-Modernidade: a fraternidade em questão. Florianópolis: FUNJAB, 2013.

SANTOS, Boaventura de Souza. Pela Mão de Alice: o social e o político na pós-modernidade. 7.ed. São Paulo: Cortez, 2000;

. A Gramática do Tempo: para uma nova cultura jurídica. 2.ed. São Paulo: Cortez 2008;

. Pensar el Estado y laSociedad:desafíosactuales. Buenos Aires: Waldhunter, 2009;

TOCQUEVILLE, Alexis de. A Democracia na América: leis e costumes. 2.ed. São Paulo: Martins Fontes, 2005.

TOSI, Giuseppe. A Fraternidade é uma Categoria Política? In: BAGGIO, Antonio Maria (Org.). 0 Princípio Esquecido: exigências, recursos e definições da fraternidade na política. Vol. 02. São Paulo: Cidade Nova, 2009.

WOLKMER, Antonio Carlos. Pluralismo Jurídico: fundamentos de uma nova cultura no direito. São Paulo: Alfa Omega, 2001.

Recebido em: 01/10/2014 / Revisado em: 25/11/2014 Aprovado em: 10/12/2014 